\title{
TU/e EN⿴HONE

\section{Selective separation of furfural and hydroxymethylfurfural from an aqueous solution using a supported hydrophobic deep eutectic solvent liquid membrane}

Citation for published version (APA):

Dietz, C. H. J. T., Kroon, M. C., Di Stefano, M., van Sint Annaland, M., \& Gallucci, F. (2018). Selective separation of furfural and hydroxymethylfurfural from an aqueous solution using a supported hydrophobic deep eutectic solvent liquid membrane. Faraday Discussions, 206, 77-92. https://doi.org/10.1039/C7FD00152E

\section{Document license:}

TAVERNE

DOI:

10.1039/C7FD00152E

Document status and date:

Published: 01/01/2018

Document Version:

Publisher's PDF, also known as Version of Record (includes final page, issue and volume numbers)

Please check the document version of this publication:

- A submitted manuscript is the version of the article upon submission and before peer-review. There can be important differences between the submitted version and the official published version of record. People interested in the research are advised to contact the author for the final version of the publication, or visit the $\mathrm{DOI}$ to the publisher's website.

- The final author version and the galley proof are versions of the publication after peer review.

- The final published version features the final layout of the paper including the volume, issue and page numbers.

Link to publication

\footnotetext{
General rights

- You may freely distribute the URL identifying the publication in the public portal. follow below link for the End User Agreement:

www.tue.nl/taverne

Take down policy

If you believe that this document breaches copyright please contact us at:

openaccess@tue.nl

providing details and we will investigate your claim.
}

Copyright and moral rights for the publications made accessible in the public portal are retained by the authors and/or other copyright owners and it is a condition of accessing publications that users recognise and abide by the legal requirements associated with these rights.

- Users may download and print one copy of any publication from the public portal for the purpose of private study or research.

- You may not further distribute the material or use it for any profit-making activity or commercial gain

If the publication is distributed under the terms of Article 25fa of the Dutch Copyright Act, indicated by the "Taverne" license above, please 


\title{
Selective separation of furfural and hydroxymethylfurfural from an aqueous solution using a supported hydrophobic deep eutectic solvent liquid membrane $\uparrow$
}

\author{
Carin H. J. T. Dietz, ${ }^{a}$ Maaike C. Kroon, (D)*b Michela Di Stefano, ${ }^{a}$ \\ Martin van Sint Annaland ${ }^{a}$ and Fausto Gallucci*a
}

\author{
Received 28th April 2017, Accepted 12th June 2017 \\ DOI: $10.1039 / c 7 f d 00152 e$
}

\begin{abstract}
For the first time, 12 different supported deep eutectic solvent (DES) liquid membranes were prepared and characterized. These membranes consist of a polymeric support impregnated with a hydrophobic DES. First, the different membranes were characterized and their stability in water and air was determined. Subsequently, the supported DES liquid membranes were applied for the recovery of furfural (FF) and hydroxymethylfurfural (HMF) from aqueous solutions. The effects of substrate properties (e.g. pore size), DES properties (e.g. viscosity) and concentrations of FF and HMF in the feed phase on the observed diffusivities and permeabilities were assessed. It was found that the addition of DES enhances the transport of FF and HMF through the polymeric membrane support. In particular, the use of the DES consisting of thymol + lidocaine (in the molar ratio $2: 1$ ) impregnated in a polyethylene support resulted in enhanced transport for both FF and HMF, and is most interesting for (in situ) isolation of FF and HMF from aqueous solutions, e.g. in biorefinery processes.
\end{abstract}

\section{Introduction}

Biomass has received enormous attention in recent years, both as a renewable raw material and an energy source. ${ }^{1}$ Cellulose and hemicellulose are the macro sugar polymers in biomass that can be hydrolysed to free sugar monomers (e.g. glucose and fructose), which can be further converted into different platform chemicals. For example, furfural (FF) and hydroxymethylfurfural (HMF) can be obtained by

${ }^{a}$ Chemical Process Intensification, Dept. Chemical Engineering and Chemistry, Eindhoven University of Technology, PO Box 513, Eindhoven, Netherlands

${ }^{b}$ Khalifa University of Science and Technology, Petroleum Institute, Chemical Engineering Department, P.O. Box 2533, Abu Dhabi, United Arab Emirates. E-mail: mkroon@pi.ac.ae

$\dagger$ Electronic supplementary information (ESI) available: Stability (EDX results and SEM images) and performance (concentration profiles of FF and HMF in the receiving phase) of the SLMs. See DOI: 10.1039/c7fd00152e 
acid hydrolysis of these sugar monomers..$^{2-4} \mathrm{FF}$ and HMF are the most investigated sugar-derived chemicals, because they are intermediates from which many other products can be made, such as monomers for bioplastics like dimethyladipate, cyclopentanediol, cyclopentanone and tetrahydrofurfurylalcohol., ${ }^{\mathbf{5}, 6}$ Moreover, they can be obtained from various renewable agricultural resources and residues from forest products. ${ }^{7-9}$

Separation, purification and solvent recovery determine the economic feasibility of the FF and HMF production process. ${ }^{10}$ The isolation of these sugarderived chemicals is the main challenge in their production. ${ }^{11}$ To prevent further conversion, in situ separation is needed. ${ }^{12}$ Liquid-liquid extraction and steam stripping are the most commonly applied isolation methods. ${ }^{\mathbf{1 3}, \mathbf{1 4}}$

Recently, various deep eutectic solvents (DESs) were evaluated for their extraction performance for sugar-derived molecules, like FF and HMF. ${ }^{15}$ DESs are mixtures of at least one hydrogen bond acceptor (HBA) and one hydrogen bond donor (HBD). ${ }^{\mathbf{1 6}, 17}$ When mixed in the proper molar ratio, they show a large decrease in melting point compared to the initial compounds. ${ }^{18}$ DESs are often termed ionic liquid analogues, as they have similar properties to ionic liquids, e.g. low vapour pressure and tunability. ${ }^{1}$ Specifically, hydrophobic DESs, discovered in $2015,{ }^{19}$ were found to be promising extractants for FF and HFM from aqueous solutions, but it was difficult to regenerate the DES after extraction. ${ }^{15}$ If these hydrophobic DESs could be impregnated in liquid membranes, their recovery would be easier and less DES would be required for FF and HMF recovery. Moreover, a liquid membrane reactor would allow for in situ FF and HMF removal, preventing further side-reactions..$^{\mathbf{2 0}-22}$

So far, DES supported liquid membranes (SLMs) have not been reported in the literature. In this paper, we present for the first time liquid impregnated membranes that are made with hydrophobic DESs. The preparation procedure is similar to the one used for the preparation of ionic liquid membranes in $2013 .^{23}$ In total 3 different polymeric hydrophobic substrates, because of wettability, and 4 different hydrophobic DESs were combined to form 12 different liquid membranes. The substrates have different pore sizes and thicknesses. The hydrophobic DESs have different viscosities and densities. Both the substrate and the DES influence the observed permeabilities and diffusivities.

First, the 12 different supported hydrophobic DES liquid membranes are characterized and their water and air stability is tested. Next, we present for the first time the recovery of FF and HMF with the hydrophobic DES impregnated SLMs. Diffusivities of both compounds (FF and HMF) through the membranes are studied and their concentrations in both the feed and receiving phase are measured. Finally, the feasibility of the new liquid membranes for FF and HMF recovery is assessed.

\section{Experimental}

\section{Membranes and chemicals}

The hydrophobic membranes "16P10A" and "M3202B", made up of ultra-high molecular weight polyethylene, were provided by Lydall Membranes, and the accurel PP2E HF polypropylene-based flat sheet membrane was provided by Membrana. The membrane pore sizes were experimentally determined using a Porolux 500, from Porometer with an uncertainty of $0.001 \mu \mathrm{m}$. The pore sizes 
can be found in Table 1 . The sources and purities (as stated by the supplier) of the chemicals used in this study are presented in Table 2.

\section{DES preparation and characterization}

Known masses of the HBA and HBD were added together in a sealed glass bottle. The masses were weighed using a "Mettler AX205" balance with an uncertainty in the measurements of $\pm 0.2 \times 10^{-4} \mathrm{~g}$. Then, the mixture was heated at $313.2 \mathrm{~K}$ in a thermostatic bath (IKA RCT basic) with a temperature controller (IKA ETS-D5) with an uncertainty in the measurement of $\pm 0.1 \mathrm{~K}$. The mixture was continuously stirred while heating using a magnetic stirrer for $2 \mathrm{~h}$. The four prepared DESs are shown in Table 3.

The density and viscosity of the DESs were measured at a temperature of 293.15 K on an Anton Paar SVM 3000/G2 type Stabinger instrument, with an uncertainty of $\pm 0.0005 \mathrm{~g} \mathrm{~cm}^{-3}$ for the density, $\pm 0.005 \mathrm{mPa}$ s for the viscosity, and $\pm 0.01 \mathrm{~K}$ for the temperature. The values obtained are listed in Table 4 .

\section{Preparation and characterization of the supported liquid membranes (SLMs)}

The membrane support was first weighed and thereafter soaked in the DES for $0.5 \mathrm{~h}$. The impregnated membrane was then wiped using a paper tissue to remove the excess DES from the surface. Thereafter, the membrane was weighed using a "Mettler AX205" balance with an uncertainty in the measurement of $\pm 0.2 \times$ $10^{-4} \mathrm{~g}$. This was repeated for all SLMs. All membrane stabilities were tested by weighing the impregnated membranes at time intervals of 2, 4, 6 and $24 \mathrm{~h}$. The membranes were characterized via scanning electron microscopy (SEM), FEI: Quanta 200 3D FEG 3 kV, spot 4; EDX Genesis software, and energy dispersive Xray spectroscopy (EDX), Phenom world: Phenom ProX: Electronic source: $\mathrm{CeB}_{6} ; 5$

Table 1 The thickness (as stated by the suppliers) and the pores sizes of the membranes used in this work

\begin{tabular}{lllll}
\hline Membrane & $\begin{array}{l}\text { Thickness } \\
(\mu \mathrm{m})\end{array}$ & $\begin{array}{l}\text { Average pore } \\
\text { size }(\mu \mathrm{m})\end{array}$ & $\begin{array}{l}\text { Smallest pore } \\
\text { size }(\mu \mathrm{m})\end{array}$ & $\begin{array}{l}\text { Biggest pore } \\
\text { size }(\mu \mathrm{m})\end{array}$ \\
\hline 16P10A & 120 & 0.585 & 0.283 & 1.359 \\
M3203B & 80 & 4.097 & 2.163 & 8.278 \\
PP2E(HF) & 170 & 0.312 & 0.234 & 0.688
\end{tabular}

Table 2 Source and purity (as stated by the supplier) of the chemicals used in this work

\begin{tabular}{lcl}
\hline Name & Purity & Source \\
\hline Furfural & $>99 \%$ & Sigma Aldrich \\
5-Hydroxymethylfurfural & $\sim 99 \%$ & Sigma Aldrich \\
$n$-Tetraoctylammonium bromide & $>96 \%$ & Sigma Aldrich \\
Decanoic acid & $>98 \%$ & Sigma Aldrich \\
Thymol & $>99 \%$ & Sigma Aldrich \\
Menthol & $\sim 99 \%$ & Sigma Aldrich \\
Lidocaine & $>99 \%$ & Sigma Aldrich
\end{tabular}


Table 3 DESs prepared in this work including their HBD, HBA, HBD : HBA ratio and abbreviation

\begin{tabular}{llll}
\hline HBD & HBA & Molar ratio & Abbreviation \\
\hline Decanoic acid & $\begin{array}{l}n \text {-Tetraoctylammonium } \\
\text { bromide }\end{array}$ & $2: 1$ & deca-N8888Br \\
Decanoic acid & Thymol & $1: 1$ & deca-thy \\
Decanoic acid & Menthol & $1: 1$ & deca-men \\
Thymol & Lidocaine & $2: 1$ & thy-lid
\end{tabular}

Table 4 Density $(\rho)$ and viscosity $(\mu)$ of the four different DESs at $293.15 \mathrm{~K}$ and atmospheric pressure (1.01 bar)

\begin{tabular}{llc}
\hline DES & $\rho\left(\mathrm{g} \mathrm{cm}^{-3}\right)$ & $\mu(\mathrm{Pa} \mathrm{s})$ \\
\hline deca-N8888Br & 0.9329 & 0.640 \\
deca-men & 0.9011 & 0.020 \\
deca-thy & 0.9318 & 0.015 \\
thy-lid & 0.9891 & 0.122
\end{tabular}

kV. Low current; EDX, ProSuite Software, before and after impregnation and after the diffusion test.

\section{Diffusion test}

The diffusion of FF and HMF through the SLMs was evaluated using a customized in-house glass diffusion cell. The glass cell has two independent compartments of $70 \mathrm{~mL}$, separated by the SLM (see Fig. 1). O-Rings were inserted on each side of the SLM. The initial solute concentrations in the feed phase were 1, 2 and $3 \mathrm{wt} \% \mathrm{FF}$ or HMF in water. Water was used as a receiving phase in all cases. Both compartments were mechanically stirred to minimize surface concentration polarization conditions at the membrane. $1 \mathrm{~mL}$ samples of each phase (feed phase and receiving phase) were taken at time intervals of 1, 2, 4, 6 and $24 \mathrm{~h}$.

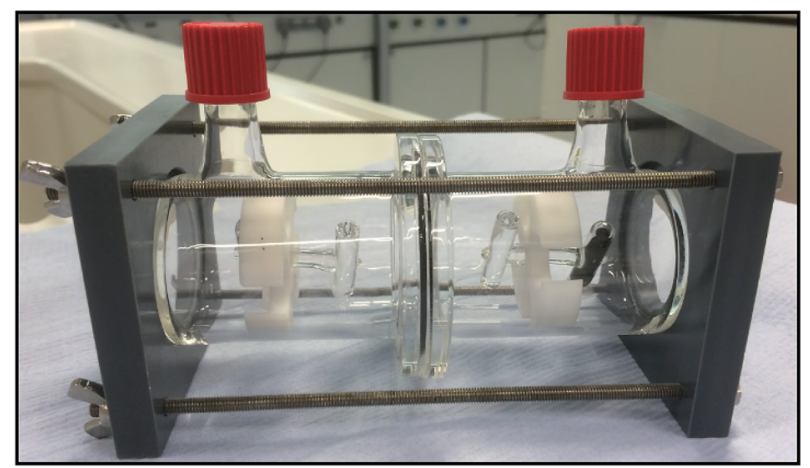

Fig. 1 Customized in-house glass diffusion cell. 


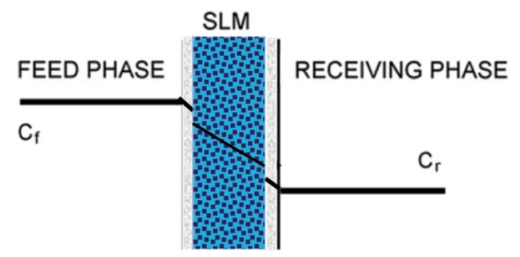

Fig. 2 Schematic drawing of the concentration profile in a supported liquid membrane (SLM) process.

\section{Analysis of FF and HMF}

The concentrations of FF and HMF in both phases (feed and receiving phase) were measured with a HPLC Agilent technology 1200 series (Agilent Technologies, Santa Clara, USA), equipped with a Multiple Wavelength Detector (G1365D) and a thermostated auto-sampler. Separation was carried out at $298.15 \mathrm{~K}$; the mobile phase composition was acetonitrile : water $(98: 2 \mathrm{v} / \mathrm{v})$ with a $1 \mathrm{~mL} \mathrm{~min}^{-1}$ flow and an injection volume of $5 \mu \mathrm{L}$, using a Jordi GEL DVB polyamine column $(250 \mathrm{~mm} \times$ $4.6 \mathrm{~mm}$, cat. no. 17010, Jordi Labs LLC, Bellingham).

\section{Calculation of permeability}

The diffusion through the membrane can be characterized by determining the permeability via eqn (1). ${ }^{22}$ Fig. 2 shows schematically the concentration profile of a solute that is transported through the supported DES liquid membrane. The transport process of the solute from the feed phase to the receiving phase involves five steps:

(1) Forced convection in the bulk of the feed solution.

(2) Solution diffusion from the bulk of the feed solution to the feed $/ \mathrm{membrane}$ interface.

(3) Diffusion across the SLM.

(4) Solution diffusion from the receiving/membrane interface to the bulk of the receiving phase.

(5) Forced convection in the bulk of the receiving phase.

In eqn (1), $J_{\mathrm{r}}$ is the mass flux of the solute (in mol $\mathrm{m}^{-2} \mathrm{~s}^{-1}$ ), $P$ is the permeability of the membrane (in $\mathrm{m} \mathrm{s}^{-1}$ ), and $C_{\mathrm{f}}$ and $C_{\mathrm{r}}$ are the concentrations of the solute in the feed and receiving phase, respectively (in $\mathrm{mol} \mathrm{m}^{-3}$ ), both containing the same solvent (water) and therefore allowing the incorporation of the distribution coefficient into the permeability $P$.

$$
J_{\mathrm{r}}=-P\left(C_{\mathrm{r}}-C_{\mathrm{f}}\right)
$$

Since the flux can be expressed as the moles of the solute transported through the membrane surface area $\left(A\right.$, in $\left.\mathrm{m}^{2}\right)$ per time unit, eqn (1) can be rewritten into eqn (2):

$$
\frac{\mathrm{d} N_{\mathrm{r}}}{\mathrm{d} t}=-P A\left(C_{\mathrm{r}}-C_{\mathrm{f}}\right)
$$

where $N_{\mathrm{r}}$, the amount of the solute in the receiving phase (in mol), can be expressed in terms of the concentration of solute as (eqn (3)): 


$$
N_{\mathrm{r}}=C_{\mathrm{r}} V_{\mathrm{r}}
$$

and where $V_{\mathrm{r}}$ is the volume of the receiving phase (in $\mathrm{m}^{3}$ ). Taking into consideration that the volume of both the receiving and feed phases were kept the same throughout the experiment (i.e., $V_{\mathrm{r}}=V_{\mathrm{f}}=V$ ), eqn (2) can also be expressed as (eqn (4)):

$$
\frac{\mathrm{d} C_{\mathrm{r}}}{\mathrm{d} t}=-\frac{P A\left(C_{\mathrm{r}}-C_{\mathrm{f}}\right)}{V}
$$

Since the flux of the solute is very large, the concentration of the receiving phase $\left(C_{\mathrm{r}}\right)$ is not negligible versus the concentration of the feed phase $\left(C_{\mathrm{f}}\right)$. Thus, $\left(C_{\mathrm{r}}-C_{\mathrm{f}}\right)$ is calculated using eqn (5) where $C_{0}$ is the initial concentration of the solute in the feed phase:

$$
C_{\mathrm{f}}=C_{0}-C_{\mathrm{r}}
$$

or equivalently (eqn (6)):

$$
\left(C_{\mathrm{r}}-C_{\mathrm{f}}\right)=2 C_{\mathrm{r}}-C_{0}
$$

Combining eqn (4) and (6) yields the differential eqn (7):

$$
\frac{\mathrm{d} C_{\mathrm{r}}}{\mathrm{d} t}=-\frac{P A\left(2 C_{\mathrm{r}}-C_{0}\right)}{V}
$$

Eqn (7) can be solved using the following boundary conditions: at $t=0, C_{\mathrm{r}}=$ 0 and $t=t, C_{\mathrm{r}}=C_{\mathrm{r}}($ eqn (8)):

$$
\ln \left(\frac{C_{0}-2 C_{\mathrm{r}}}{C_{0}}\right)=-\frac{2 P A}{V} t
$$

which shows that $\ln \left[\left(C_{0}-2 C_{\mathrm{r}}\right) / C_{0}\right]$ is a linear function of $t$. The permeability for the solute is calculated using eqn (8), from the slope $m$ of the plot of $\ln \left[\left(C_{0}-2 C_{\mathrm{r}}\right) /\right.$ $\left.C_{0}\right]$ versus $t$ via (eqn (9)):

$$
P=-\frac{m V}{2 A}
$$

\section{Results and discussion}

First, three different polymeric membrane substrates (PP2E HF, M3203B and 16P10A) were selected consisting of different (hydrophobic) polymeric materials and with different pore sizes. The permeability of FF and HMF through the three selected plain membrane supports (without any DES impregnated in the support) was studied as a control experiment. The initial concentrations of FF and HMF in the feed phase were set to $1 \mathrm{wt} \%$ in water. The concentrations of FF and HMF in the receiving and feed phases were measured over time and the permeability values were calculated from the slopes of the plot of $\ln \left[\left(C_{0}-2 C_{\mathrm{r}}\right) / C_{0}\right]$ using eqn (9). Fig. 3 shows the plots used for the calculation of the FF and HMF 


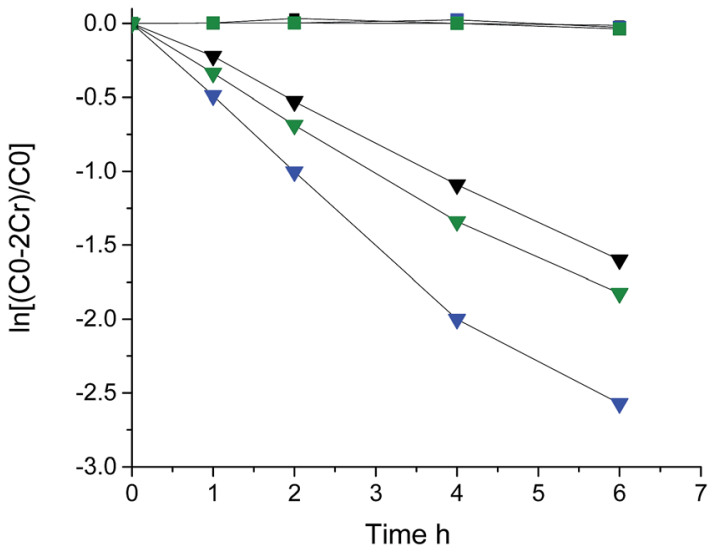

Fig. 3 Plots of $\ln \left[\left(C_{0}-2 C_{r}\right) / C_{0}\right]$ vs. operation time for the transport of FF and HMF through the different plain membrane supports: (square) HMF; (triangle) FF; (black) PP2E HF; (blue) M3203B; (green) 16P10A.

permeabilities through the different plain membrane supports. As a linear dependence is obtained, it can be assumed that external mass transfer limitations are negligible. The permeability values for each compound through the plain membrane supports are presented in Table 5. It can be noticed that the permeability for HMF through all the plain membrane supports is very low, while the permeability for FF is much higher.

The big difference in permeability between FF and HMF can be explained by the difference in hydrophobicity of the two components. HMF (completely watermiscible) is much more hydrophilic than FF (maximum water solubility at $298 \mathrm{~K}$ is only $77 \mathrm{~g} \mathrm{~L}^{-1}$, as stated by the supplier), while all three polymeric membrane supports are hydrophobic. Therefore, FF diffuses faster through the plain membrane supports. The highest permeabilities are observed for M3203B, which was expected as this support has the largest pore size and smallest thickness (see Table 1).

Next, the three plain membrane supports were filled with the four different hydrophobic DESs. The percentage of pore filling was gravimetrically determined by the weight increase compared to the volume of the pores, as determined from the porosity. The results are presented in Table 6 . It can be concluded that the pores of the PP2E HF membrane support are relatively easily filled, while the

Table 5 Permeability ${ }^{a}$ of $\mathrm{FF}$ and HMF through the different plain membrane supports

\begin{tabular}{llll}
\hline \multicolumn{2}{l}{ Permeability $^{a} 10^{-4}\left[\mathrm{~m} \mathrm{~s}^{-1}\right]$} & \\
\cline { 2 - 3 } & PP2E & & \\
& HF & M3203B & 16 P10A \\
\hline FF & 3.31 & 5.17 & 3.76 \\
HMF & 0.02 & 0.03 & 0.03
\end{tabular}

${ }^{a}$ Standard uncertainties are $u(P)=0.02 \mathrm{~m} \mathrm{~s}^{-1}$. 
Table $6 \%$ pores filled of different membrane supports and different DESs

$\% \mathrm{v} / \mathrm{v}$ filled pores by membrane type

\begin{tabular}{llll}
\hline & \multicolumn{2}{c}{$\% \mathrm{v} / \mathrm{v}$ filled pores by membrane type } \\
\cline { 2 - 4 } DESs & PP2E HF & M3203B & 16P10A \\
\hline deca-N8888Br & 107 & 87 & 78 \\
deca-thy & 104 & 85 & 73 \\
deca-men & 102 & 84 & 72 \\
thy-lid & 102 & 80 & 75 \\
\hline
\end{tabular}

M3203B and 16P10A membrane supports are not filled completely. However, permeability tests with water did not show any water transport through all three impregnated membranes (while water transport is possible through all three plain membrane supports), indicating that most pores were indeed filled.

The big difference between the membrane supports is that PP2E HF has a neat pore structure, while M3203B and 16P10A have lamellar structures. Thus, it can be concluded that the nice pore structure of the PP2E HF membrane support can be more easily filled than the pores from the lamellar structure membranes (M3203B and 16P10A). Even though the pore size of M3203B is larger, not all pores are completely filled, probably also because of the lamellar structure of this membrane. The smaller calculated volume filling of $75 \%$ (on average) for 16P10A as compared to M3203B (which both have lamellar structures) can be attributed to the fact that 16P10A has smaller pores than M3203B.

The stability of supported liquid membranes is one of the major limitations of their application. ${ }^{24,25}$ Therefore, it was of interest to investigate the air and water stability of the supported DES liquid membranes. All SLMs were tested for $24 \mathrm{~h}$ in air and in water for their weight loss over time. The results over time are shown in Fig. S1 in the ESI, $\uparrow$ and the results after $24 \mathrm{~h}$ are depicted in Fig. 4.

It is clear that the lamellar structure of M3203B and 16P10A leads to higher losses of the DESs from these supports as compared to the nice pore structure of PP2E HF. The pore size of the M3203B membrane support is largest; this can explain the larger loss in weight for this support as compared to 16P10A. Thus, the pore size has also a large impact on the stability of the SLMs.

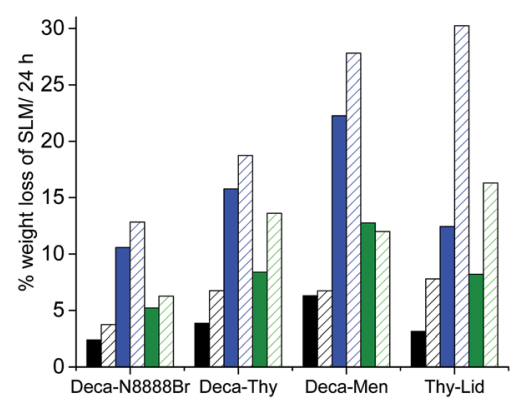

Fig. 4 Weight loss (\%) of the SLMs after $24 \mathrm{~h}$ in air (solid bars) and after $24 \mathrm{~h}$ of the transport experiment (pattern filled bars) based on different DESs and membrane supports: (black) PP2E HF; (blue) M3203B; (green) 16P10A. 
Even though the DESs applied are hydrophobic, the loss in water is always higher than the loss in air. Thus, the applied DESs apparently have a higher solubility in water as compared to their vapour pressure. Indeed, small amounts of DES were detected in the water phase after $24 \mathrm{~h}$ (e.g., a maximum of $2 \%$ of the total amount of thymol that was present in the six SLMs containing thymol was detected in the water phase after $24 \mathrm{~h}$ of the diffusion experiment using HPLC). The other DES' constituents were not detected in the water phase after $24 \mathrm{~h}$ of the diffusion experiment.

From the four DESs, the deca-men DES, impregnated in all three supports, showed the largest weight loss in air, most likely because this DES has the largest vapour pressure. The deca-thy DES, impregnated in all three supports, showed the largest weight loss in water, as this DES is the least hydrophobic. The decaN8888Br DES presented the lowest weight loss in all cases. This can be related to the lowest volatility and water solubility of this DES compared to the others.

The DES losses of the prepared SLMs can be further analysed and characterized using SEM-EDX before and after $24 \mathrm{~h}$ of diffusion. For these experiments only the SLMs with the deca-N8888Br DES can be used, because this DES contains an atom that is DES-specific (i.e., Br), which can be easily detected using EDX. The other DESs do not contain a different element compared to the membrane supports and are therefore not easily analysed using EDX. All results are shown in Table S1 in the ESI. $\uparrow$ The results of the SLMs consisting of PP2E HF and decaN8888Br are also shown in Table 7.

With this technique the loss of $\mathrm{Br}$ (coming from the deca-N8888Br DES) after $24 \mathrm{~h}$ diffusion may seem even larger than the results from the weight loss experiment. However, it should be noted that with this technique only the surface concentrations are measured. Therefore, the loss of DES from the pores could be much lower. Again, water permeability tests showed that the pores are still filled with DES, as no water was able to pass through the SLMs, also after $24 \mathrm{~h}$ of the diffusion experiment. To further prove this, SEM images were obtained of a large surface area of the SLM before and after $24 \mathrm{~h}$ of the diffusion experiments. Closeup images are presented next to clearly show any differences.

First, SEM images of the empty plain membrane supports were obtained and are shown in Fig. 5. These images clearly show the pore structure of PP2E HF and the lamellar structure of M3203B and 16P10A.

In Fig. S2-S4 in the ESI, $\uparrow$ the SEM images of all the SLMs before and after $24 \mathrm{~h}$ of diffusion are shown. Fig. 6 only shows the SEM images of the SLMs consisting

Table 7 Atomic concentration of the elements $\mathrm{C}, \mathrm{O}$ and $\mathrm{Br}$ measured on the surface of the empty membrane (PP2E HF), deca-N8888Br-filled membrane and after $24 \mathrm{~h}$ transport of $\mathrm{FF}$

\begin{tabular}{lccc}
\hline & \multicolumn{2}{c}{ Atomic concentration } & \\
\cline { 2 - 4 } & & & $\begin{array}{c}\text { After 24 h } \\
\text { diffusion }\end{array}$ \\
Symbol & Empty & Before diffusion & 84.54 \\
$\mathrm{C}$ & 92.80 & 81.54 & 14.66 \\
$\mathrm{O}$ & 7.20 & 16.75 & 0.80 \\
$\mathrm{Br}$ & 0.00 & 1.72 &
\end{tabular}



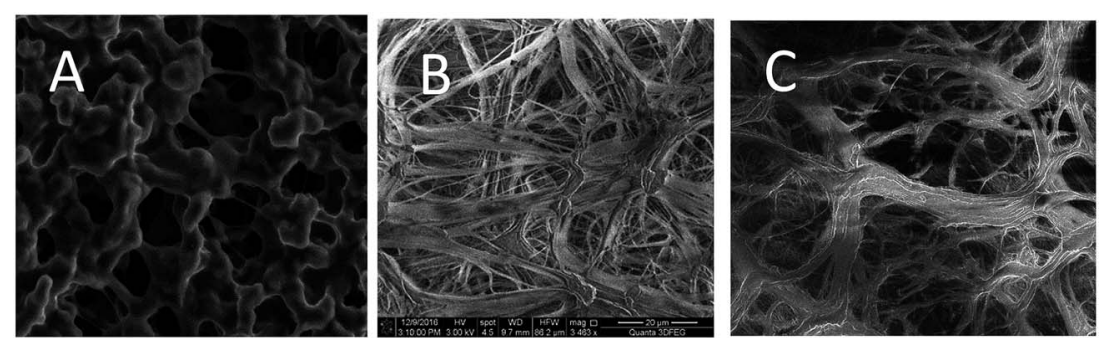

Fig. 5 SEM images of the empty plain membrane supports: (A) PP2E HF; (B) M3203B; (C) 16P10A.
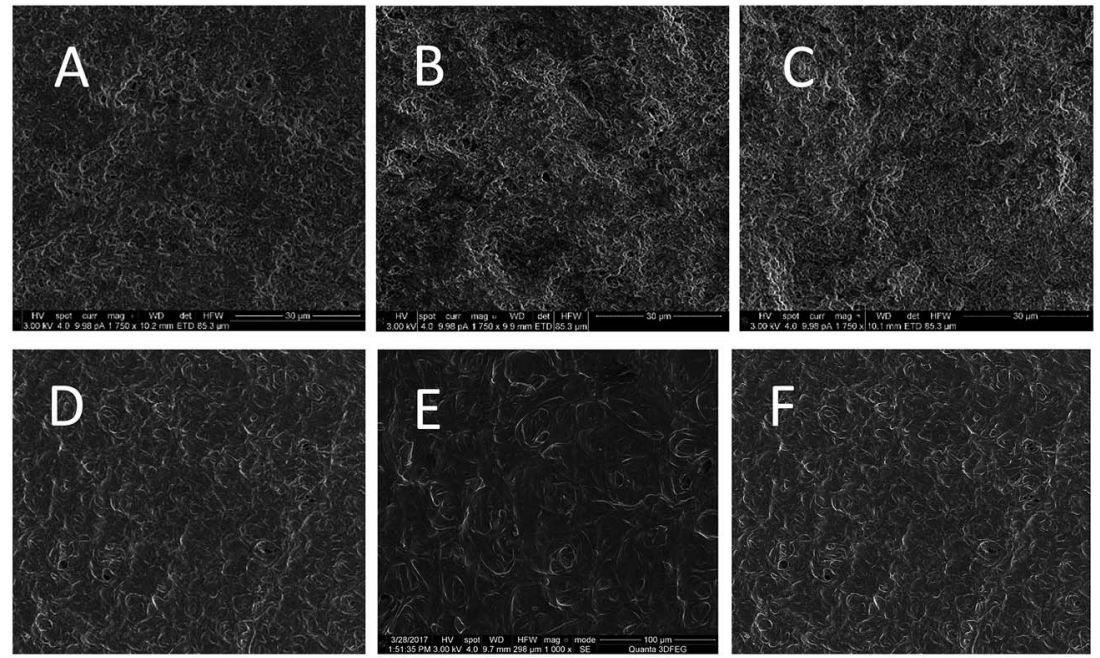

Fig. 6 SEM images of SLMs before and after $24 \mathrm{~h}$ of the diffusion experiments: (A) PP2E HF filled with deca-N8888Br; (B) PP2E HF filled with deca-N8888Br after $24 \mathrm{~h}$ of water transport; (C) PP2E HF filled with deca-men after $24 \mathrm{~h}$ of water transport; (D) M3203B filled with deca-N8888Br; (E) M3203B filled with deca-N8888Br after $24 \mathrm{~h}$ of water transport; (F) M3203B filled with deca-men after $24 \mathrm{~h}$ of water transport.

of the PP2E HF and M3203B supports with the DESs deca-N8888Br and deca-men before and after $24 \mathrm{~h}$ diffusion. These SLMs were selected because: (i) deca$\mathrm{N} 8888 \mathrm{Br}$ was used for the EDX experiments and showed a large loss of $\mathrm{Br}$ from the pore surface, (ii) deca-men showed the largest weight loss in water after $24 \mathrm{~h}$, (iii) M3203B showed the largest weight loss of all the supports, and (iv) PP2E HF has a different pore structure compared to M3203B. Even though relatively large weight losses were measured for all SLMs before, the SEM images (together with the EDX mapping) show that most of the pores of all the types of membranes are still filled after $24 \mathrm{~h}$ of the diffusion experiment. This means that the newly prepared SLMs are probably more air and water stable than estimated from surface techniques like EDX analysis.

The experimental concentrations of FF and HMF in the feed phase and in the receiving phase as a function of the run time for all the twelve different SLMs were 
monitored. Fig. S5-S8 in the ESI $\dagger$ present these plots of FF/HMF concentration in the feed and receiving phase for all the twelve different SLMs. The measured FF concentrations in the feed and in the receiving phase for the SLMs prepared with the deca-men DES are also shown in Fig. 7.

It can be observed that the sum of the concentrations in the feed and receiving phase remained constant for all SLMs. Because the amount of DES in the SLM is very limited compared with the volumes of both the receiving and feed phases ( $<50 \mathrm{mg} v s .70 \mathrm{~g}$ ), the amount of solute remaining in the DES is negligible compared to the amount in the two phases. The permeation rate of FF through the M3203B-deca-men SLM is faster than through the other two SLMs prepared with deca-men, which can be explained by the larger pore size and smaller thickness of M3203B compared to the other supports, leading to faster FF permeation through the membrane.

The initial concentration in the feed and the concentrations in the receiving phase were used to calculate the individual permeability $(P)$ of FF and HMF through the different SLMs. These permeability values were calculated from the slopes of the plot of $\ln \left[\left(C_{0}-2 C_{\mathrm{r}}\right) / C_{0}\right]$ for both compounds versus time using eqn (9). As an example, Fig. 8 shows the plot used for the calculation of the FF and HMF permeabilities through the SLMs impregnated with deca-thy, with a starting concentration of $1 \mathrm{wt} \%$. Fig. 9 shows the FF and HMF permeabilities in the same SLMs for a starting concentration of $3 \mathrm{wt} \%$. The FF and HMF permeabilities for all the other SLMs at feed concentrations of 1, 2 and $3 \mathrm{wt} \%$ are shown in Fig. S9-S12 in the ESI. $\dagger$ An overview of the obtained permeability values for each compound (FF or HMF) through the different SLMs with and without DES are presented in Table 8.

All SLMs impregnated with deca-N8888Br showed lower permeabilities than the same supports impregnated with the three other DESs. This can be explained by the fact that deca-N8888Br has the highest viscosity and therefore presents the highest mass transfer limitations.

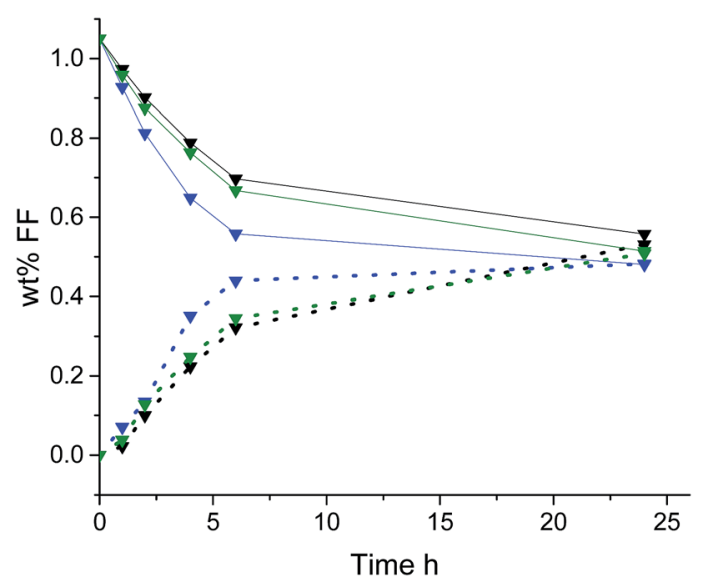

Fig. 7 Plot of the wt\% concentration of $F F$ in the feed and receiving phase in time for the thy-lid based SLMs: (black) PP2E HF; (blue) M3203B; (green) 16P10A, starting with a 1 wt\% $\mathrm{FF}$ in the feed phase at $293.2^{\circ} \mathrm{C}$. 


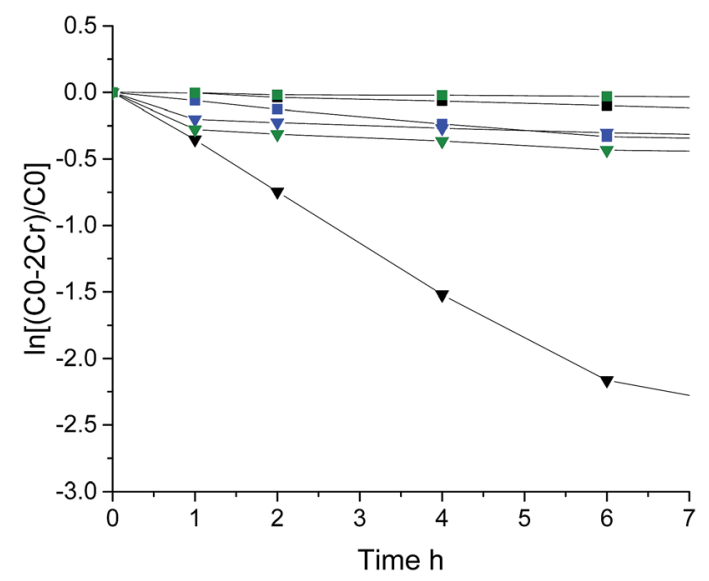

Fig. 8 Plot of $\ln \left[\left(C_{0}-2 C_{r}\right) / C_{0}\right]$ vs. operation time for the transport of 1 wt\% FF and HMF through the different deca-thy-SLMs: (square) HMF; (triangle) FF; (black) PP2E HF; (red) M3203B; (green) 16P10A.

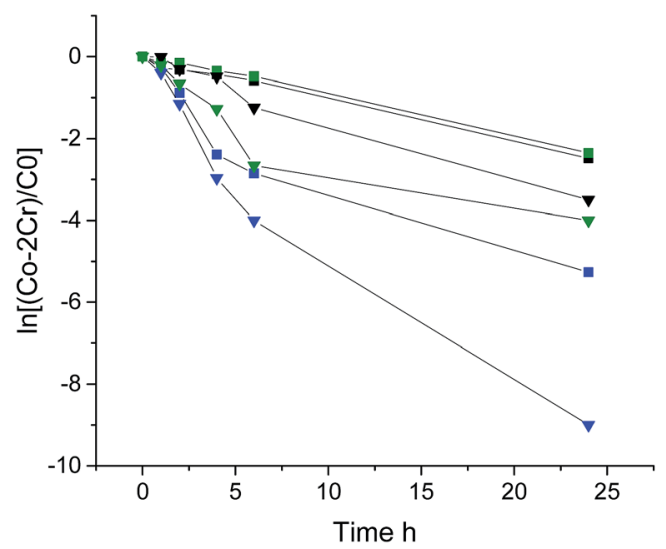

Fig. 9 Plot of $\ln \left[\left(C_{0}-2 C_{r}\right) / C_{0}\right]$ vs. operation time for the transport of 3 wt\% of FF and $\mathrm{HMF}$ through the different thy-lid-SLMs: (square) HMF; (triangle) FF; (black) PP2E HF; (red) M3203B; (green) 16P10A.

However, the DES viscosity does not fully explain the observed trends. For example, thy-lid has a ten times higher viscosity than both deca-men and decathy, but the permeability of both FF and HMF through the thy-lid-SLMs is the highest. Thus, mass transfer limitations cannot explain this observation. Instead, molecular interactions are most likely responsible for the fact that this DES has a higher affinity for FF and HMF, and therefore the permeation through this DES is better, even though the viscosity is slightly higher. Thus, it can be concluded that the interaction of the solute with the DES has the largest influence on the permeability.

At low initial solute concentrations ( $1 \mathrm{wt} \%$ of FF and HMF in the feed phase), the permeability values of the empty plain membrane supports were in most cases 


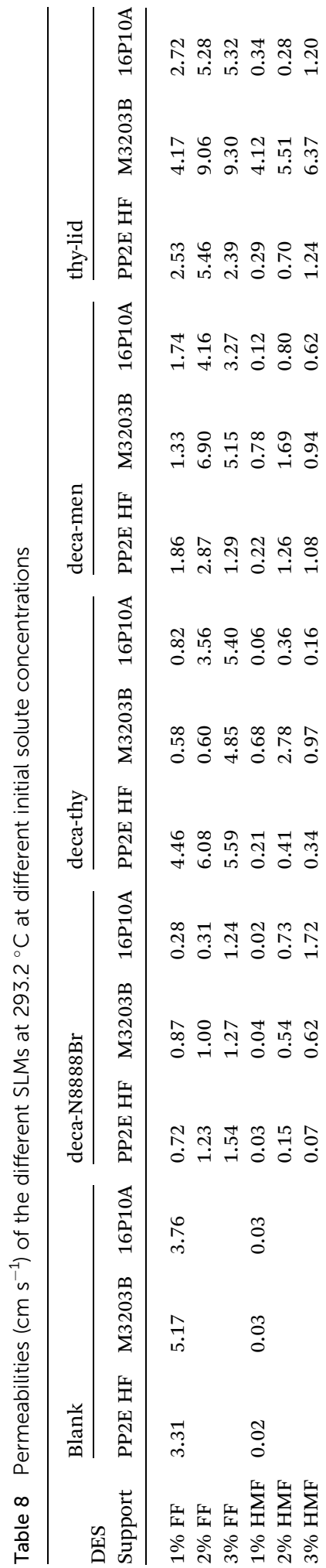


higher than the permeability values of the supported DES liquid membranes. This could be explained by the fact that the SLMs introduce an additional masstransfer resistance (i.e., in the DES phase) for the transport of FF and HMF. However, when the starting concentrations of both species in the feed phase increase to $2 \mathrm{wt} \%$, the $\left(C_{\mathrm{f}}-C_{\mathrm{r}}\right)$ is higher and the permeability increases. Most importantly, in several cases a higher permeability is reached compared with the empty plain membrane supports, showing that the addition of the DES can enhance the transport of FF and HMF through the polymeric membrane support. At even higher initial FF and HMF concentrations in the feed phase (3wt\%), the obtained permeability values hardly increase any further. Apparently, at these initial concentrations, the maximum permeability is reached. At that moment, the mass transfer through the DES phase becomes the limiting step or multicomponent effects may start to play a role.

For HMF, the plain membrane supports always have lower permeability than the SLMs. The reason is that the SLMs are very hydrophobic, while the HMF is slightly hydrophilic. Thus, the HMF does not stay close to the membrane. Instead, all DESs have a better interaction with HMF and therefore can drive the HMF through the membrane.

For FF, it depends on the DES whether the plain membrane support or the SLM shows the highest permeability. For example, for PP2E HF the permeability for FF is higher when it is impregnated with the deca-thy DES than for the plain membrane support. However, when this support is impregnated with the other DESs, the obtained permeabilities are lower compared to the plain membrane support. This is because of the additional mass transfer resistance introduced by the addition of the DES.

Therefore, it strongly depends on the interaction between the DES and the solute (FF) if it is beneficial to impregnate the membrane supports with the DES to increase its performance. Very high permeabilities for FF were found for the following SLMs: PP2E HF with deca-thy, PP2E HF with thy-lid, M3203B with thylid and 16P10A with thy-lid. Thus, in general, it can be concluded that the DESs containing thymol show increased interaction with FF (and HMF) and are the most suitable for impregnation in the SLMs.

The highest permeabilities for both HMF and FF are found for the thy-lid DES impregnated in the M3202B support. The support of this SLM has the largest pores and smallest thickness, and the applied DES shows the highest interaction with both FF and HMF. Therefore, this is the most interesting SLM for (in situ) isolation of FF and HMF from aqueous solutions, e.g. in biorefinery processes.

Currently, the separation of solutes/macromolecules by polymeric membranes in industry is mostly based on the molecular size of the solutes and less on their structure. The main advantage of the SLMs as described in this work is that they enable the selective separation of the solutes based on their molecular structure, by interaction with the DES. It should be noted that DESs are tuneable, so that the most suitable DESs can be designed for specific recovery processes. Moreover, the impregnation of the DESs in SLMs will increase the specific surface areas, decrease the amount of DES required and make it easier to recover solutes from the DES phase as compared to other extraction processes. The results of this study are encouraging and suggest that the designed SLMs could be incorporated in future reaction/separation processes. 


\section{Conclusions}

In this study we outlined for the first time the possibility of using SLMs based on hydrophobic DESs for the selective separation of FF and HMF. The permeability of these compounds through SLMs based on four different DESs (deca-N8888Br, deca-thy, deca-men and thy-lid) immobilized in three different hydrophobic polymeric membrane supports (PP2E HF, M3203B and 16P10A) was studied. Larger pores (e.g., in M3203B) led to faster diffusion of FF and HMF, but also to increased losses of the DESs. Higher diffusion was also achieved using DESs with lower viscosity and stronger interactions with FF and HMF. Thus, DESs can be tuned for FF and HMF recovery. The most promising result is the high permeability for both FF and HMF using the SLM consisting of M3202B with thy-lid, where the addition of the DES significantly enhanced the transport of FF and HMF through the polymeric membrane support.

\section{Acknowledgements}

This work was performed under the framework of the Chemelot InSciTeHorizontal project and with contributions from the European Regional Development Fund (ERDF) within the framework of OP-Zuid and with contributions from the province of Brabant and Limburg and the Dutch Ministry of Economic Affairs. Thanks to the OGO-Energy students of the Technical University of Eindhoven for their help in the experiments, and the Membrane Materials and Processes group, Prof. Dr. Ir. K. Nijmeijer and Dr. Z. Borneman for sharing their expertise and allowing the use of their lab facilities.

\section{References}

1 D. J. G. P. van Osch, L. J. B. M. Kollau, A. van den Bruinhorst, S. Asikainen, M. M. A. Rocha and M. C. Kroon, Phys. Chem. Chem. Phys., 2017, 19, 2636-2665.

2 V. Ordomsky, J. van der Schaaf, J. C. Schouten and T. A. Nijhuis, ChemSusChem, 2012, 5, 1812-1819.

3 N. Perret, A. Grigoropoulos, M. Zanella, T. D. Manning, J. B. Claridge and M. J. Rosseins, ChemSusChem, 2016, 9, 521-531.

4 L. Hu, RSC Adv., 2012, 2, 11184.

5 Q. Deng, J. Xu, P. Han, L. Pan, I. Wang, X. Zhang and J. Zou, Fuel Process. Technol., 2016, 148, 361-366.

6 J. Guo, G. Xu, Z. Han, Y. Zhang, Y. Fu and Q. Guo, ACS Sustainable Chem. Eng., 2014, 2, 2259-2266.

7 C. Sievers, M. B. Valenzuela-Olarte, T. Marzialetti, I. Musin, P. K. Agrawal and C. W. Jones, Ind. Eng. Chem. Res., 2009, 48, 1277-1286.

8 K. Ya, G. Wu, T. La fleur and C. Jarvis, Renewable Sustainable Energy Rev., 2014, 38, 663-676.

9 K. de Oliveira Vigier, G. Chatel and F. Jerome, ChemCatChem, 2015, 7, 12501260.

10 C. Lena, C. M. J. Blumenthal, J. Ulbrich, F. Schwering, V. Langrehr, T. Turek, U. Kunz, K. Leonhard and R. Palkovits, ACS Sustainable Chem. Eng., 2016, 4, 228-235.

11 P. Bhaumik and P. L. Dhepe, ACS Catal., 2013, 3, 2299-2303. 
12 S. Sitthisa and D. E. Resasco, Catal. Lett., 2011, 141, 784-791.

13 J. R. Croker and R. G. Bowrey, Ind. Eng. Chem. Fundam., 1984, 23, 480-484.

14 W. Deng, M. Liu, Q. Zhang, X. Tan and Y. Wang, Chem. Commun., 2010, 46, 2668-2670.

15 C. H. J. T. Dietz, M. C. Kroon, F. Galluci and M. Sint Annaland, J. Chem. Eng. Data, DOI: 10.1021/acs.jced.7b00184.

16 A. P. Abbott, G. Capper, D. L. Davies, R. K. Rasheed and V. Tambyrajah, Chem. Commun., 2003, 70-71.

17 Y. Dai, J. van Spronsen, G. J. Witkamp, R. Verpoorte and Y. H. Choi, Anal. Chim. Acta, 2013, 766, 61-68.

18 Q. Zhang, K. de Oliveira Vigier, S. Royer and F. Jérôme, Chem. Soc. Rev., 2012, 41, 7108 .

19 D. J. G. P. van Osch, L. F. Zubeir, A. van den Bruinhorst, M. M. A. Rocha and M. C. Kroon, Green Chem., 2015, 17, 4518.

20 M. F. San Roman, E. Bringas, R. Ibanez and I. Ortiz, J. Chem. Technol. Biotechnol., 2010, 85, 2-10.

21 M. Althuluth, J. P. Overbeek, H. J. van Wees, L. F. Zubeir, W. G. Haije, A. Berrouk, C. J. Peters and M. C. Kroon, J. Membr. Sci., 2015, 484, 80-86.

22 F. J. Hernandez-Fernandez, P. D. los Ríos, M. Rubio, F. T. Alonso, D. Gómez and G. A. Víllora, J. Membr. Sci., 2007, 293, 73-80.

23 A. Panigrahi, S. Raju Pilli and K. Mohanty, Sep. Purif. Technol., 2013, 107, 7078.

24 R. Fortunato, C. A. M. Afonso, M. A. M. Reis and J. G. Crespo, J. Membr. Sci., 2004, 242, 197-209.

25 R. Fortunato, C. A. M. Afonso, J. Benavente, E. Rodriguez-Castellón and J. G. Crespo, J. Membr. Sci., 2005, 256, 216-223. 